\title{
BREVES COMENTÁRIOS AO CRIME DE LAVAGEM DE DINHEIRO
}

\section{BRIEF COMMENTS ON MONEY LAUNDERING CRIME}

\author{
Marcos Alves Da Silva ${ }^{1}$ \\ Carlos Eduardo Rocha Mezzadri²
}

\section{RESUMO}

O objetivo deste trabalho é analisar o crime de lavagem de dinheiro, sua origem, a necessidade de tipificação diante de fenômenos de terrorismo, tráfico de entorpecentes e armas, bem como corrupção. Busca-se, além do estudo de sua origem, a definição de seu bem jurídico tutelado, bem como o estudo do tipo objetivo, elemento subjetivo do tipo, as fases de aperfeiçoamento do crime e, ainda, a importância do combate e prevenção da lavagem de dinheiro, face à nocividade que tal modalidade criminosa apresenta à sociedade como um todo.

\begin{abstract}
The present work has the goal of analyse the laudering money crime, its origen, the needing to criminalization against events like terrorism, weapons and trafic as well corruption. This seeking goes beyond the studyng of its origin the protected legal good, just as, the studying about the objective criminal Law, the subjective elemente of the crime, the improving stages of crime and still, the importance of countering and preventing the money laundering by the enormous danger that this criminal category cause for the society at all.
\end{abstract}

\footnotetext{
1 Doutor em Direito Civil pela Universidade do Estado do Rio de Janeiro - UERJ (2012). Mestre em Direito pela Universidade Federal do Paraná - UFPR (2001). Graduado em Direito pela Universidade Federal do Paraná (1995). Advogado. Professor da Escola da Magistratura do Paraná EMAP. Professor da Fundação Ministério Público do Estado do Paraná FEMPAR. Professor Permanente do Programa de Mestrado em Direito Empresarial e Cidadania do UNICURITIBA. Realiza estágio Pós-Doutoral na Universidade Nova de Lisboa (2016/2017). 2 Aluno especial do Mestrado em Direito Empresarial e Cidadania do Centro Universitário Curitiba.
} 


\section{1 - INTRODUÇÃO}

O crime de lavagem de dinheiro, ou branqueamento de capitais, como também é conhecido, é recente na história jurídica nacional. Introduzido há pouco mais de 20 anos no direito brasileiro, sofreu no ano de 2012 atualização legislativa que extinguiu o rol taxativo de crimes antecedentes, ampliando sobremaneira as possibilidades de configuração da infração penal.

De importância ímpar para o combate da criminalidade organizada, a figura da lavagem de dinheiro deve ser esmiuçada para seu correto entendimento e alcance, podendo então atingir seus objetivos de enfrentamento ao tráfico de entorpecentes, terrorismo, corrupção e tantas outras modalidades criminosas.

Para tanto, com o presente artigo, busca-se analisar o bem jurídico protegido pelo tipo penal, bem como o tipo objetivo que a reforma legislativa de 2012 trouxe significativa ampliação do alcance punitivo, além de se analisar o tipo objetivo e o elemento subjetivo do tipo.

Faz-se também rápida análise do caráter transnacional do crime de branqueamento de capitais, haja vista a pluralidade de transações tendentes a dissimular a origem ilícita dos bens ou valores que, normalmente, se verificam em diversos países.

Estuda-se ainda a construção doutrinária segundo a qual o delito de lavagem de dinheiro é composto de três fases, quais sejam, a ocultação ou dissimulação, a de mascaramento e a de integração.

Ao final, trata-se da importância da prevenção e combate à lavagem de dinheiro, sua nocividade à sociedade como um todo, por ser crime que fomenta uma diversidade de outras condutas criminosas, como por exemplo a corrupção.

Rapidamente, são abordados alguns instrumentos estatais que visam o combate ao crime de branqueamento de capitais, como por exemplo a ENCCLA, estratégia que congrega 
diversos braços do Estado, e que desde 2003 articula esforços no combate à esta modalidade criminosa.

\section{2 - CONCEITO E HISTÓRICO}

O fenômeno criminoso de lavagem de dinheiro, também conhecido como branqueamento de capitais, é figura antiga que remonta ao início do século $\mathrm{XX}$, contudo, a tipificação legal é bastante recente, remontando às décadas de 80 e 90 do século XX.

O termo "lavagem de dinheiro" remete à idéia de que o dinheiro auferido ilicitamente é, por assim dizer, sujo, necessitando ser "lavado" para se tornar limpo. Segundo a Procuradora da República, Carla Veríssimo de Carli, a expressão teria sido usada como resultado do uso, por grupos mafiosos, de lavanderias de roupa, para dar aparência legal ao dinheiro obtido por meios ilegais, vejamos o que Luiz Felipe Mallmann de Magallhães conta sobre a origem do termo:

“Uma origem lendária leva a AL Capone, que teria comprado em 1928, em Chicago, uma cadeia de lavanderias que era usada como fachada, onde teria lhe permitido fazer depósitos bancários de notas de baixo valor nominal, habituais nas vendas de lavanderia, mas resultantes do comércio de bebidas alcoólicas interdito pela Lei Seca e de outras atividades criminosas como a exploração da prostituição, do jogo e a extorsão."

Michele Sindona, conhecido banqueiro italiano condenado por diversos crimes e ligado à máfia siciliana, definiu a lavagem de dinheiro da seguinte forma: "Laundering money is to switch the black money, or dirty money... [to] clean Money"2, ou seja, "lavar dinheiro é trocar o dinheiro sujo, pelo dinheiro limpo".

Como dito, embora o fenômeno seja antigo, somente nas últimas décadas do século XX é que se observa a tipificação, sendo que, em 1978, na Itália, surge a primeira legislação sobre o tema, através do Decreto-Lei n 59 de 21 de março de 1978, sendo posteriormente convertido na lei $\mathrm{n}^{\mathrm{o}}$ 191, de 18 de maio de 1978, vindo a criminalizar a substituição de dinheiro advindo de determinados ilícitos por dinheiro que tenha aspecto de legalidade, vejamos:

\footnotetext{
1 MAGAlHÃES. Luiz Felipe Mallmann de. O crime de "Lavagem de Dinheiro". Disponível em < https://www.luizfelipemagalhaes.com.br/artigo/42/crime-de-lavagem-de-dinheiro>

${ }^{2}$ Relatório "The Cash Conection: Organizes Crime, Financial Institutions, and Money Laudering" da President's Comission on Organized Crime de 1985, in: https://www.ncjrs.gov/pdffiles1/Digitization/166517NCJRS.pdf
} 
opo l'art. 648 del codice penale e' aggiunto il seguente:

"Art. 648-bis - (Sostituzione di denaro o valori provenienti da rapina aggravata, estorsione aggravata o sequestro di persona a scopo di estorsione).

- Fuori dei casi di concorso nel reato, chiunque compie fatti o atti diretti a sostituire denaro o valori provenienti dai delitti di rapina aggravata, di estorsione aggravata o di sequestro di persona a scopo di estorsione, con altro denaro o altri valori, al fine di procurare a se' o ad altri un profitto o di aiutare gli autori dei delitti suddetti ad assicurarsi il profitto del reato, e' punito con la reclusione da quattro a dieci anni e con la multa da lire un milione a venti milioni. Si applica l'ultimo comma dell'articolo precedente".

Seguiu-se a legislação Americana, de 1987, a francesa, de 1987 e, finalmente, a brasileira, em 1998, através da lei no 9.613/1998 que posteriormente foi alterada pela lei $12.683 / 12$

A legislação brasileira atual tipifica a ocultação ou dissimulação da origem, localização, disposição, movimentação ou propriedade de bens, direitos ou valores provenientes, direta ou indiretamente, de infração penal, vejamos ${ }^{3}$ :

“Art. $1^{\circ}$ Ocultar ou dissimular a natureza, origem, localização, disposição, movimentação ou propriedade de bens, direitos ou valores provenientes, direta ou indiretamente, de infração penal.

$\S 1^{0}$ Incorre na mesma pena quem, para ocultar ou dissimular a utilização de bens, direitos ou valores provenientes de infração penal:

I - os converte em ativos lícitos;

II - os adquire, recebe, troca, negocia, dá ou recebe em garantia, guarda, tem em depósito, movimenta ou transfere

III - importa ou exporta bens com valores não correspondentes aos verdadeiros.

\footnotetext{
${ }^{3} \mathrm{O}$ texto reproduzido já traz as mudanças da lei12.682/2012
} 
$\S 2^{\underline{o}}$ Incorre, ainda, na mesma pena quem:

I - utiliza, na atividade econômica ou financeira, bens, direitos ou valores provenientes de infração penal;

II - participa de grupo, associação ou escritório tendo conhecimento de que sua atividade principal ou secundária é dirigida à prática de crimes previstos nesta Lei.

$\S 3^{\circ}$ A tentativa é punida nos termos do parágrafo único do art. 14 do Código Penal.

$\S 4$ o A pena será aumentada de um a dois terços, se os crimes definidos nesta Lei forem cometidos de forma reiterada ou por intermédio de organização criminosa.

§ 5ㅇ A pena poderá ser reduzida de um a dois terços e ser cumprida em regime aberto ou semiaberto, facultando-se ao juiz deixar de aplicá-la ou substituí-la, a qualquer tempo, por pena restritiva de direitos, se o autor, coautor ou partícipe colaborar espontaneamente com as autoridades, prestando esclarecimentos que conduzam à apuração das infrações penais, à identificação dos autores, coautores e partícipes, ou à localização dos bens, direitos ou valores objeto do crime.

O que é importante ter em mente, é que a idéia principal na criminalização do fenômeno de branqueamento de capitais não é apenas a criação de mais um tipo penal, consistindo em novo esforço de combate à criminalidade. Como destacado pelo Professor Sérgio Fernando Moro:

"O que é essencial é privar o criminoso dos ganhos decorrentes de sua atividade, ou seja, confiscar o produto do crime. É a consagração do velho adágio de que o "crime não deve compensar" 4.

Ou seja, conclui-se que para prevenção da criminalidade, além de punir o agente com penas privativas de liberdade, há que se alijar o criminoso do produto do crime, não podendo usufruir daquilo que ilegalmente angariou, de sorte que, se não puder gozar daquilo que foi ilegalmente conseguido, não valerá a pena cometer o crime.

\section{3 - BEM JURÍDICO TUTELADO}

\footnotetext{
${ }^{4}$ MORO, Sergio Fernando. CRIME DE LAVAGEM DE DINHEIRO. Editora Saraiva, 2010.
} 
Ainda que brevemente e sem descer à minúcia, importante tecer alguns comentários acerca do bem jurídico tutelado pela figura típica da lavagem de dinheiro.

O bem jurídico é o ponto fixo de todos os tipos penais, elemento da estrutura de qualquer tipo penal. Mais que isso, a lesão ou ameaça de lesão ao bem jurídico é pressuposto da punibilidade, de tal sorte que é imprescindível a definição do bem jurídico tutelado.

Até hoje persiste discussão acerca de qual seria o bem jurídico tutelado pelo crime de lavagem de capitais, não existindo ainda consenso.

Neste diapasão, emergem três principais teorias sobre o bem jurídico tutelado, as quais se passa a abordar a seguir. A primeira sustenta que o bem jurídico protegido seria o mesmo protegido pela figura típica do crime antecedente. A segunda define como objeto de proteção do crime de lavagem a administração da justiça e, por fim, uma terceira teoria defende que a ordem econômica seria o bem jurídico tutelado.

A primeira corrente defende que o bem jurídico tutelado no crime antecedente é também objeto tutelado no crime de lavagem de dinheiro. Preteritamente, a tipificação do crime de branqueamento de capitais nasceu da necessidade de se enfrentar o tráfico de entorpecentes e, evidentemente, a dissimulação dos valores obtidos com tal modalidade criminosa. Como o crime de tráfico de entorpecentes tem por bem jurídico tutelado a saúde pública, seria também este o bem jurídico defendido pela figura da lavagem de dinheiro.

Cabe aqui uma observação: O antigo art. $1^{\circ}$ da Lei 9.613/1998, primeira codificação da lavagem de dinheiro em nosso país, previa um rol taxativo de crimes antecedentes, dentre os quais o tráfico de entorpecentes supra mencionado. Previa também a extorsão mediante seqüestro, o qual possui como bem jurídico tutelado a liberdade individual. Sob tal aspecto, se o crime antecedente fosse a extorsão mediante seqüestro, o bem jurídico tutelado passaria então a ser a liberdade individual.

Ou seja, por tal teoria, o crime de lavagem de dinheiro não teria um bem jurídico próprio, mas dependeria do crime antecedente.

Para Vicente Greco Filho, a lavagem de dinheiro é praticada para ocultar e assegurar o proveito dos crimes antecedentes e, pela lei 9.613/1998 estabelecer vinculação processual de competência para o julgamento do crime de branqueamento, é indicativo de que a lavagem de 
dinheiro acompanha o crime antecedente, não apenas no plano da competência, mas também no plano do direito material e tutela de bens jurídicos, vejamos:

“(...) o crime de lavagem acompanha o crime antecedente, não apenas no plano da competência, mas também no plano do direito material e tutela de bens jurídicos"

Há vários argumentos que se colocam contrários à essa primeira tese, como por exemplo a independência entre o crime antecedente e o crime de lavagem, consagrada pelo artigo $2^{\circ}$ da lei $12.683 / 2012$, o qual dispõe o seguinte:

“Art. $2^{\circ} \mathrm{O}$ processo e julgamento dos crimes previstos nesta Lei:

\section{$(\ldots)$}

II - independem do processo e julgamento das infrações penais antecedentes, ainda que praticados em outro país, cabendo ao juiz competente para os crimes previstos nesta Lei a decisão sobre a unidade de processo e julgamento.”

Salvo melhor juízo, a dependência do bem jurídico tutelado pelo crime antecedente, defendida pela primeira corrente, está de dissonância com o artigo $2^{\circ}$ a lei $12.683 / 2012$, vez que prevê a independência de um delito em relação ao outro.

Há que se considerar também que a legislação brasileira, que criminaliza o branqueamento de capitais, prevê uma pena única para o delito, independentemente de qual seja o crime anterior, ou seja, a pena será a mesma, para a lavagem decorrente de tráfico de drogas, corrupção, extorsão mediante seqüestro.

Uma segunda teoria defende que o bem jurídico tutelado é a administração da justiça. Segundo os defensores desta corrente, o crime de lavagem de dinheiro apagaria os rastros deixados pelo delito anterior, prejudicando, desta forma, a persecução criminal e, por consequiência o funcionamento da justiça.

Segundo lecionam Bottini e Badaró:

“... a administração da Justiça como bem jurídico tutelado pela lavagem de dinheiro trás característica de favorecimento (arts. $\underline{348}$ e $\underline{349}$ do $\underline{\mathrm{CP}}$ ), pois o comportamento

\footnotetext{
${ }^{5}$ GRECO FILHO, Vicente. Tipicidade, bem jurídico e lavagem de valores. In: Costa, José de Faria; Silva, Marco Antonio Marques da (Coords.). Direito penal especial, processo penal e direitos fundamentais: visão luso-brasileira. São Paulo: Quartier Latin, 2006. P.162-163
} 
afeta a capacidade da justiça de exercer suas funções de investigação, processamento, julgamento e recuperação do produto do delito. A lavagem aqui coloca em risco a operacionalidade e a credibilidade do sistema de Justiça, por utilizar complexas transações a fim de afastar o produto de sua origem ilícita e com isso obstruir seu rastreamento pelas autoridades públicas. "6

Em contraposição à idéia de que a administração da justiça seja o objeto de proteção da lavagem, argumenta-se, principalmente, que não há dolo específico de afetar o regular funcionamento da justiça. De fato, nos parece que o criminoso, ao dissimular a origem ilícita do capital, não pretende especificamente dificultar a administração da justiça, mas sim proteger o dinheiro que ilegalmente obteve. Tal entendimento aproximaria o crime de lavagem de dinheiro do crime de favorecimento real, esculpido pelo artigo 349 do código penal brasileiro, configurando verdadeira "superproteção" do bem jurídico do crime antecedente.

Finalmente há uma terceira teoria que defende que o objeto de proteção da lavagem de capitais é a ordem econômico-financeira, posto que, o dinheiro ilícito que é recolocado na economia, causa instabilidade por ferir a livre iniciativa, o sistema de concorrência e as relações de consumo.

Dentre os defensores da tese, temos Luiz Flávio Gomes, Raúl Cervini e Wilian Terra, que afirmam:

“com a criação de tipos penais especiais direcionados a combater os procedimentos de lavagem de capitais, busca-se fundamentalmente proteger a normalidade do tráfego jurídico no mundo da economia" e mais adiante finalizam dizendo que o crime de lavagem de dinheiro "atinge interesses metapessoais ou transindividuais, e por esse motivo o bem juridicamente protegido não poderia ser outro senão a própria ordem socioeconômica", .

\footnotetext{
${ }^{6}$ BOTTINI, Pierpaolo Cruz; BADARÓ, Gustavo Henrique. Lavagem de dinheiro: aspectos penais e processuais penais: comentários à Lei 9.613/98, com alterações da Lei 12.683/2012. São Paulo: RT, 2012.

7 CERVINI, Raúl; OlIVEIRA, William Terra de; GOMES, Luiz Flávio. Lei de lavagem de capitais: comentários à Lei 9.613/98. São Paulo: Revista dos Tribunais, 1998, p. 321
} 
Importante mencionar também o entendimento de Carla Veríssimo de Carli, para quem a lavagem de dinheiro apresenta quatro implicações, vejamos:

a) distorções econômicas: pois a lavagem de dinheiro pode resultar em um grande abalo ou até mesmo na perda do controle da econômica pelo Estado, pois quem pratica o crime de Lavagem disponibiliza produtos muitas vezes com preços inferiores aos de mercado; $\boldsymbol{b})$ risco à integridade e à reputação do sistema financeiro: problemas de liquidez aos bancos podem ocorrer quando grandes somas de dinheiro lavado chegam às instituições financeiras ou delas rapidamente desaparecem. Além disso, a lavagem de dinheiro pode 'manchar' a reputação e a confiabilidade de uma instituição financeira; ) diminuiçãa dos recursos governamentais: A lavagem de dinheiro dificulta a arrecadação dos impostos e diminui a receita tributária porque as transações a ela relacionadas ocorrem na economia informal; $\boldsymbol{d})$ repercussões socioeconômicas: possibilita o crescimento das atividades criminais, o que traz maiores problemas sociais e aumenta os custos implícitos e explícitos do sistema penal como um todo." 8

A corrente que defende a ordem econômica como bem jurídico tutelado pelo crime de lavagem de dinheiro é a predominante na doutrina pátria, podendo-se argumentar ainda que, por mais que se possa identificar outros interesses na norma, seu objetivo principal é a proteção da normalidade da ordem social e econômica.

De fato, a tese segundo a qual o bem jurídico atacado pelo crime de branqueamento de capitais seria a ordem econômica nos parece a mais robusta, posto que, mesmo que se possa enxergar outros bens jurídicos penais alcançados pelo tipo, é inegável que a ordem econômicofinanceira é o principal deles. Tal conclusão é possível até mesmo pela leitura da exposição de motivos da lei 9.613/1998, que em seu item 33, prevê o seguinte:

8 DE CARLI, Carla Veríssimo. Lavagem de dinheiro: ideologia da criminalização e análise do discurso. Porto Alegre: Verbo Jurídico, 2012. 
33. Inclui-se nessas considerações a defesa de uma economia saudável, pelo que os referidos delitos integram, como antecedentes do novo tipo penal, os crimes contra o Sistema Financeiro Nacional (Lei no 7.492, de 16 de junho de 1986). ${ }^{9}$

Como se vê, a mens legis, inegavelmente, é a "defesa de uma economia saudável, isso quando ainda se previa um rol taxativo para os crimes antecedentes, não restando outra conclusão diversa, segundo a qual o bem jurídico penal tutelado pelo crime de lavagem de dinheiro é a ordem econômica.

\section{4 - CARACTERÍSTICA TRANSNACIONAL}

$\mathrm{O}$ crime de branqueamento de capitais pode ser enquadrado como um "crime de colarinho branco", ou seja, é modalidade criminosa sofisticada, envolvendo complexo planejamento que, por vezes, extrapola os limites territoriais nacionais.

Muito embora o crime de lavagem possa se configurar nos limites territoriais nacionais, pode assumir contornos internacionais. Hipoteticamente, o crime, ou crimes, antecedentes podem ser praticados em um país e o produto destes delitos enviado para outros países, tudo com o intuito de dificultar a persecução criminal e, obviamente, ocultar os valores oriundos da atividade criminosa.

Conforme observa o Ministro Sérgio Fernando Moro, na já mencionada obra "Crime de Lavagem de Dinheiro", na hipótese de não existir criminalização do branqueamento de capitais no país de destino do dinheiro produto de crime antecedente, praticado no país de origem, no qual a lavagem é tipificada, o país de destino não pode tomar providências sem que seja efetivado pedido de colaboração do país de origem, por não possuir jurisdição.

De outra forma, caso a conduta da lavagem já seja criminalizada no país de destino dos recursos maculados, pode-se iniciar a persecução criminal, posto que, muito embora continue a não ter jurisdição sobre o crime de origem, goza de jurisdição autônoma em relação ao crime de lavagem.

Haja vista ser corriqueira a transferência internacional de recursos obtidos ilegalmente, com o fito de se dificultar o rastreamento, há a imperiosa necessidade de se promover a

\footnotetext{
9 Item 33 da exposição de motivos da lei 9.613/1998. In: file://C:/Users/User/Downloads/Exposicao\%20de\%20Motivos\%20Lei\%209613\%20(1).pdf
} 
cooperação internacional para investigação de tal modalidade criminosa, daí então o caráter transnacional da figura em estudo.

Neste sentido, podemos citar a recomendação $n^{\circ} 1$ do Grupo de Ação Financeira $(\mathrm{GAFI} / \mathrm{FATF})^{10}$, que determina que países deveriam "aplicar o crime de branqueamento de capitais a todos os crimes graves, por forma a abranger o conjunto mais alargado de infracções subjacentes. ”Entretanto, permite também que os crimes antecedentes possam ser definidos por referência apenas a crimes graves.

\section{5 - TIPO OBJETIVO, ELEMENTO SUBJETIVO E FASES DO CRIME DE}

\section{LAVAGEM DE CAPITAIS}

\section{1 - Tipo objetivo}

Como já dito anteriormente, o crime de lavagem de dinheiro foi introduzido no direito brasileiro através da lei $\mathrm{n}^{\circ}$ 9.613/1998, a qual previa um rol taxativo de delitos antecedentes, sendo que, com a atualização legislativa de 2012, introduzida pela lei 12.683 daquele ano, a qual passou a regular que, a lavagem de dinheiro se caracterizaria com a ocultação ou dissimulação da natureza, origem, localização, disposição, movimentação ou propriedade de bens, direitos ou valores provenientes, direta ou indiretamente, de infração penal.

Desta sorte, seguindo a tendência internacional, ampliou-se a abrangência do tipo penal, abandonando o rol taxativo da legislação de 1998, dando lugar ao termo "infração penal”.

Segundo esta nova redação, até mesmo contravenções penais podem ser tidas como delito antecedente do crime de lavagem de capitais. Por tal raciocínio, o dinheiro obtido, por exemplo, como resultado do chamado "jogo do bicho", que é uma contravenção penal, se ocultada ou dissimulada sua natureza ou origem, configuraria a figura da lavagem de dinheiro.

Da análise do tipo, percebe-se a existência de dois núcleos, ou seja, "ocultar" e "dissimular". Ocultar significa esconder, encobrir e dissimular, por sua vez, significa disfarçar, fingir, ou seja, os dois núcleos do tipo são os verbos ocultar e dissimular.

\section{2 - Elemento Subjetivo}

10 O Grupo de Ação Financeira contra a Lavagem de Dinheiro e o Financiamento do Terrorismo (GAFI/FATF) é uma organização intergovernamental cujo propósito é desenvolver e promover políticas nacionais e internacionais de combate à lavagem de dinheiro e ao financiamento do terrorismo. 
No que tange elemento subjetivo do tipo, o crime somente pode ser punido se demonstrado o dolo. Há que ser demonstrada a vontade livre e consciente de ocultar ou dissimular bens, direitos ou valores, cuja origem seja uma infração penal. Por evidente, não se pune a conduta culposa, uma vez que há que se demonstrar a vontade específica do agente de ocultar ou dissimular o resultado do crime antecedente,

Podemos concluir também que se trata de dolo genérico, uma vez que o tipo não requer a presença de elemento subjetivo especial.

Vejamos o seguinte julgado do STJ sobre o tema:

PENAL. CRIME DE LAVAGEM DE DINHEIRO. TIPICIDADE. PENA. DOSIMETRIA.

\section{ILEGALIDADE DETECTADA. FALTA DE FUNDAMENTAÇÃO.}

1 - O crime de lavagem de dinheiro tipifica-se desde que o agente saiba que o montante pecuniário auferido, por meio de dissimulação, é produto de crime antecedente. Não se exige que tenha o agente sido condenado, especificamente, pelo ilícito penal que antecede a reciclagem dos valores.

2 - Elemento subjetivo (dolo) constatado nas instâncias ordinárias com base em profunda e ampla dilação probatória que, por óbvio, não se submete ao crivo mandamental e restrito da impetração. (grifo nosso).

3 - Em habeas corpus somente há possibilidade de se imiscuir na dosimetria quando demonstrada flagrante ilegalidade, como ocorre na espécie, dado que foi a culpabilidade, na primeira fase, e a continuidade delitiva, na terceira, sopesadas com afirmações vagas e genéricas, desprovidas de fundamentação e, quiçá, concreta.

4 - Habeas corpus não conhecido. Ordem concedida de ofício apenas para reduzir a pena a 3 anos e 6 meses de reclusão, no regime inicial aberto e substituí-la por duas restritivas de direitos (prestação pecuniária e serviço comunitário) a serem especificadas pelo Juízo das execuções penais.

(HC 309.949/DF, Rel. Ministra MARIA THEREZA DE ASSIS MOURA, SEXTA TURMA, julgado em 03/03/2015, DJe 09/03/2015)

\section{3 - As três fases do crime de lavagem de dinheiro}


Para atingir o objetivo de dissimulação dos recursos ou bens obtidos ilicitamente, o sujeito ativo do crime de lavagem percorre três fases, que são descritas por BOTTINI E BADARÓ $^{11}$, como sendo:

$1^{\text {a }}$ fase: etapa de ocultação: Neste momento inicial o criminoso busca o distanciar o bem ou valor da origem ilícita, por exemplo, através da fragmentação em quantias menores que não chamem a atenção das autoridades ${ }^{12}$. Ouso citar como exemplo desta primeira fase do crime de lavagem de capitais, caso que se tornou célebre na jurisprudência brasileira, por ter condenado um ex-presidente da República como incurso no tipo penal da lavagem de dinheiro. Trata-se da ação penal $n^{\circ}$ 5046512-94.2016.4.04.7000/PR, que tramitou pela $13^{\text {a }}$ Vara Criminal Federal de Curitiba. Em referida ação discutia-se a ocultação de bem supostamente recebido pelo ex-presidente Luiz Inácio Lula da Silva (um apartamento triplex), como vantagem indevida resultado de um antecedente crime de corrupção passiva. A defesa alegou, em relação a este fato específico, que o apartamento triplex nunca foi do ex-Presidente, que dele nunca teve a propriedade ou a posse.

Contudo, concluiu o Juízo que para configuração da lavagem de dinheiro não haveria a necessidade de transferência formal da propriedade do imóvel. Asseverou o então Juiz Sérgio Moro que:

\begin{abstract}
307. Afinal, nem a configuração do crime de corrupção, que se satisfaz com a solicitação ou a aceitação da vantagem indevida pelo agente público, nem a caracterização do crime de lavagem, que pressupõe estratagemas de ocultação e dissimulação, exigiriam para sua consumação a transferência formal da propriedade do Grupo OAS para o ex-Presidente Luiz Inácio Lula da Silva.
\end{abstract}

308. Não se está, enfim, discutindo questões de Direito Civil, ou seja, a titularidade formal do imóvel, mas questão criminal, a caracterização ou não de crimes de

\footnotetext{
${ }^{11}$ BADARÓ, Gustavo Henrique; BOTTINI, Pierpaolo Cruz. Lavagem de dinheiro: aspectos penais e processuais penais: comentários à Lei 9.613/1998, com as alterações da Lei 12.683/2012. São Paulo. Editora Revista dos Tribunais. 2016. p. 81.

12 O artigo 6으, § 2, I, da CIRCULAR № 3.461 do Banco Central do Brasil, que consolida as regras sobre os procedimentos a serem adotados na prevenção e combate às atividades relacionadas com os crimes previstos na Lei ำ 9.613, de 3 de março de 1998, define o valor de $R \$ 10.000,00$ (dez mil reais) para identificação das operações que, realizadas com uma mesma pessoa, conglomerado financeiro ou grupo, em um mesmo mês calendário, superem, por instituição ou entidade, em seu conjunto, tal valor
} 
corrupção e lavagem. Não se deve nunca esquecer que é de corrupção e lavagem de dinheiro do que se trata. ${ }^{13}$

Referida decisão foi confirmada pela Corte Federal da $4^{\mathrm{a}}$ Região, em julgamento da apelação. Vejamos o trecho que cuida da ocultação do patrimônio:

30. O tipo penal da lavagem de dinheiro abarca o propósito de ocultar ou dissimular a localização, disposição, movimentação ou propriedade de bens, direitos ou valores. A ausência de título translativo do imóvel é compatível com a prática do delito, revelando a intenção de ocultar ou dissimular a titularidade ou a origem do bem.

31. Preservada a condenação por crime único de lavagem de dinheiro. As práticas narradas (aquisição, reforma e decoração do imóvel), embora pareçam distintas, inserem-se no mesmo contexto de ocultação e dissimulação. ${ }^{14}$

Como visto, o caso retratado é emblemático em se reconhecer o crime de lavagem de dinheiro pela ocultação e dissimulação de valores ou bens, constituindo perfeito exemplo da primeira fase do branqueamento de capitais, ou seja, a ocultação do bem que de fato foi recebido como vantagem indevida.

$2^{\text {a }}$ fase: etapa de mascaramento ou dissimulação do capital, na qual, o criminoso se vale de transações financeiras diversas, para afastar os valores de sua origem, geralmente transações bancária e imobiliárias, em países distintos ${ }^{15}$, tudo com o intuito de dificultar o rastreamento dos valores. Pode-se citar como exemplo o envio de dinheiro, já convertido em moeda estrangeira para o exterior, em contas de terceiro, cheques de viagem ao portador, etc.

$3^{\mathrm{a}}$ fase: Finalmente, os autores citam a última fase, ou fase de integração, ato final da lavagem com reintrodução do dinheiro na economia formal, revestido com aparência de licitude, ou seja, são simulações de negócios lícitos, como operações de importação ou exportação, com preços super ou subfaturados, compra de imóveis com valores fora do preço de real de mercado.

13 Trecho da sentença prolatada pelo então Juiz Federal Sérgio Fernando Moro, nos autos de ação penal sob no 5046512-94.2016.4.04.7000/PR, que tramitou pela 13를 Vara Criminal Federal de Curitiba.

${ }^{14}$ Trecho do acórdão da apelação criminal no 5046512-94.2016.4.04.7000/PR - TRF-4. Relator: João Pedro Gebran Neto.

${ }^{15}$ Caráter transnacional do crime de lavagem de dinheiro, abordado no item 4 do presente artigo. 
Insta salientar, contudo, que para consumação do tipo penal em análise basta a configuração da primeira fase, ou seja, é suficiente que se demonstre a ocultação dos valores ou bens para que se realize o núcleo do tipo (ocultação ou dissimulação).

Ou seja, é de se concluir que a consumação se dá no momento em que o agente pratica uma ação que envolva "ocultar" ou "dissimular" a natureza, origem, localização, disposição, movimentação ou propriedade do bem, direito ou valor.

\section{6 - A IMPORTÂNCIA DA PREVENÇÃO E COMBATE À LAVAGEM DE}

\section{DINHEIRO}

Não somente a criminalidade violenta, como por exemplo o tráfico de drogas e armas se vale da lavagem de dinheiro para dar aparência de licitude aos bens e valores indevidamente angariados, mas também os criminosos de colarinho branco buscam legitimar o produto de seus crimes, sejam estes crimes tributários ou de corrupção ativa ou passiva.

No dizer da já citada Procuradora Regional da República da $4^{\text {a }}$ Região, Carla Veríssimo de Carli, que integra o grupo de trabalho a respeito da Estratégia Nacional de Combate à Corrupção e à Lavagem de dinheiro - Encla, "então um dos grandes danos da lavagem é reforçar a impunidade dos crimes que foram cometidos anteriormente" 16 .

De fato, permitir que o criminoso usufrua do produto do crime gera enorme sentimento de impunidade e, em última análise, descrédito do sistema de justiça. Neste sentido, Ricardo Saad, diretor do Departamento de Recuperação de Ativos do Ministério da Justiça afirma que:

“ o crime de lavagem de dinheiro é extremamente nocivo à sociedade porque o criminoso que quer lavar dinheiro não está preocupado com o lucro ou qualquer coisa assim então ele aplica recursos em algumas atividades ilegais sem objetivo de lucro, como ele não tem objetivo de lucro ele pode aplicar preço de mercado melhor para poder circular o dinheiro porque ele não quer ter o lucro, ele quer simplesmente fazer circular o dinheiro". ${ }^{17}$

\footnotetext{
${ }^{16} \mathrm{O}$ crime de lavagem de dinheiro e os danos causados à sociedade. In: http://www.fetecpr.org.br/ocrime-de-lavagem-de-dinheiro-e-os-danos-causados-a-sociedade/ acessada em 01/12/2019.

${ }^{17}$ Idem.
} 
Ou seja, combater o crime de branqueamento de capitais importa não somente combater o tráfico de drogas e de armas, mas também consiste no enfrentamento da criminalidade de colarinho branco, à corrupção de modo geral.

Exatamente por isso que se deve implementar ações que visem o aperfeiçoamento do combate à lavagem de dinheiro, posto que, com isso, combater-se-ia uma série de delitos que sangram a economia nacional.

Neste contexto, imperioso citar os esforços da Estratégia Nacional de Combate à Corrupção e à Lavagem de Dinheiro - ENCCLA.

Segundo descrito na web page da ENCCLA, “A Estratégia Nacional de Combate à Corrupção e à Lavagem de Dinheiro (ENCCLA), criada em 2003, é a principal rede de articulação para o arranjo e discussões em conjunto com uma diversidade de órgãos dos Poderes Executivo, Legislativo e Judiciário das esferas federal e estadual e, em alguns casos, municipal, bem como do Ministério Público de diferentes esferas, e para a formulação de políticas públicas voltadas ao combate àqueles crimes. ${ }^{18}$

Como se vê, a ENCCLA nasceu com a missão de articular a atuação dos mais diversos órgãos públicos que atuam no combate a corrupção e a lavagem de dinheiro, figuras típicas intimamente ligadas e, sob a coordenação da Secretaria Nacional de Justiça, do Ministério da Justiça, órgãos do Poder Executivo, Legislativo, Judiciário e também do Ministério Público, são traçadas metas anuais para aperfeiçoamento do combate à corrupção e lavagem de capitais $^{19}$.

Dentre os muitos órgãos governamentais que atuam no combate e prevenção ao delito de lavagem, podemos citar principalmente o Banco Central, cujo papel é regulamentar, monitorar e fiscalizar o Sistema Financeiro Nacional, exigindo que instituições financeiras bancárias implementem procedimentos e controles de prevenção à lavagem de dinheiro, devendo comunicar indícios de crimes ao Conselho de Controle de Atividades Financeiras COAF (atualmente Unidade de Inteligência Financeira).

O antigo COAF e que atualmente possui a denominação de Unidade de Inteligência Financeira que, segundo a MP 893/2019, é responsável por produzir e gerir informações de

\footnotetext{
18 http://enccla.camara.leg.br/quem-somos

${ }^{19}$ https://www.cnj.jus.br/cnj-propoe-elaborar-metodologia-para-coletar-dados-sobre-corrupcao-e-lavagemde-dinheiro/
} 
inteligência financeira para a prevenção e o combate à lavagem de dinheiro, ao financiamento do terrorismo e ao financiamento da proliferação de armas de destruição em massa e promover a interlocução institucional com órgãos e entidades nacionais, estrangeiros e internacionais que tenham conexão com a matéria.

Internacionalmente podemos citar o Grupo de Ação Financeira - GAFI/FAFT, entidade criada em 1989, numa iniciativa dos países componentes do G-7, que promove políticas internacionais para combater a lavagem de dinheiro, o financiamento do terrorismo e outras ameaças à integridade do Sistema Financeiro Nacional. Atualmente o Gafi possui cerca de 35 países membros diretos, além de mais de 150 países membros dos diversos Organismos regionais vinculados ao GAFI, como é o caso do Grupo de Ação Financeira da América Latina (GAFILAT). ${ }^{20}$

Como visto, diversos são os órgãos nacionais e internacionais que buscam o enfrentamento da lavagem de dinheiro, tamanha a nocividade da prática para a ordem financeira e motor de crimes mais graves como tráfico internacional de drogas, armas e terrorismo

\section{7 - CONCLUSÃO}

Como visto ao longo do artigo, o crime de lavagem de dinheiro é comportamento antigo, verificado desde o início do século XX, nascido com o intuito de legitimar o produto de crimes da máfia.

Muito embora fenômeno antigo, apenas entre o fim da década de 70 e início da década de 80 é que o branqueamento de valores passou a receber atenção legislativa, vindo a ser criminalizado em diversos países. No Brasil, apenas no fim da década de 90 é que se editou a lei 9.613/1998, que finalmente criminalizou a ocultação ou dissimulação de bens ou valores oriundos direta ou indiretamente de infração penal.

Legislação nascida não apenas da necessidade de enfrentamento da figura de lavagem, mas também como obrigação internacional assumida pelo Brasil mediante diversos tratados, a lavagem de dinheiro é ainda controversa em muitos pontos, resultado certamente de sua recente introdução no direito pátrio.

${ }^{20}$ https://www.bcb.gov.br/estabilidadefinanceira/lavagemdinheiro 
Mais recente ainda é a grande exposição do termo na mídia, resultado, sem dúvida, dos diversos escândalos de corrupção que assombraram o país e acabaram por tornar o crime de lavagem de capitais voz corrente.

Embora ainda jovem, a figura em estudo levou à prisão não apenas a cúpula das maiores construtoras do país, mas também um ex-presidente da República, condenado por corrupção e lavagem de dinheiro e diversos outros políticos de alto escalão.

Se olharmos apenas os resultados apresentados pela conhecida operação "lava-jato", segundo apontamentos recentes, os 5 anos de investigações, completados em março de 2019, culminaram em 242 condenações contra 155 pessoas, em 50 processos sentenciados por lavagem de dinheiro, corrupção ativa e passiva, fraude à licitação, organização criminosa, evasão de divisas, lavagem de dinheiro, tráfico internacional de drogas, crime contra a ordem econômica, embaraço à investigação de organização criminosa e falsidade ideológica.

As cifras são impressionantes, chocam pela magnitude dos valores desviados. Segundo dados da Agencia Brasil ${ }^{21}$, no período da operação, R $\$ 2,5$ bilhões de reais foram devolvidos à Petrobras, a principal vítima dos desvios, conforme determinação da Justiça - o que corresponde a uma média de R \$ 1,37 milhão por dia devolvido aos cofres públicos desde 2014 . Segundo consta da webpage, restam ainda 11,5 bilhões a serem devolvidos para o erário, inclusive à petrolífera, conforme acordos já celebrados com a Justiça Federal.

A Agência Brasil informa, por fim, que no total dos 13 acordos de leniência com empresas implicadas no esquema de corrupção, está previsto ainda o ressarcimento de $\mathrm{R} \$ 13$ bilhões de reais. O Ministério Público Federal espera ainda de que o valor total apurado chegue a R $\$ 40$ bilhões de reais.

Como dito, os dados são estarrecedores!

A mensagem das forças estatais é clara, a população não suporta mais os absurdos índices de criminalidade, seja ela violenta ou de colarinho branco e, corruptos contumazes, habituados à histórica impunidade, se vêem acuados diante dos esforços e avanços no combate à corrupção e lavagem de dinheiro.

21 http://agenciabrasil.ebc.com.br/justica/noticia/2019-03/lava-jato-completa-cinco-anos-com-155pessoas-condenadas 
Desta sorte, conclui-se que o aperfeiçoamento do instituto da lavagem de dinheiro, o combate e a prevenção desta modalidade criminosa é essencial para o aperfeiçoamento da sociedade.

\section{REFERÊNCIAS}

BADARÓ, Gustavo Henrique; BOTTINI, Pierpaolo Cruz. Lavagem de dinheiro: aspectos penais e processuais penais: comentários à Lei 9.613/1998, com as alterações da Lei 12.683/2012. São Paulo. Editora Revista dos Tribunais. 2016. p. 81.

BOTTINI, Pierpaolo Cruz; BADARÓ, Gustavo Henrique. Lavagem de dinheiro: aspectos penais e processuais penais: comentários à Lei $\underline{9.613} / 98$, com alterações da Lei 12.683/2012. São Paulo: RT, 2012.

CERVINI, Raúl; OLIVEIRA, William Terra de; GOMES, Luiz Flávio. Lei de lavagem de capitais: comentários à Lei 9.613/98. São Paulo: Revista dos Tribunais, 1998, p. 321.

CUNHA, Ana Karla de Jesus Barbosa. http://www.emerj.tjrj.jus.br/paginas/trabalhos_conclusao/1semestre2016/pdf/AnaKarladeJesu sBdaCunha.pdf. 2016.

DE CARLI, Carla Veríssimo. Lavagem de dinheiro: ideologia da criminalização e análise do discurso. Porto Alegre: Verbo Jurídico, 2012.

GRECO FILHO, Vicente. Tipicidade, bem jurídico e lavagem de valores. In: Costa, José de Faria; Silva, Marco Antonio Marques da (Coords.). Direito penal especial, processo penal e direitos fundamentais: visão luso-brasileira. São Paulo: Quartier Latin, 2006. P.162163.

FLORES, Andréa; CAMAPUM, Rodrigo Alencar Machado. O combate ao crime de lavagem de dinheiro no direito interno e internacional. Revista Jurídica, [S.1.], v. 2, n. 55, p. 467 484, abr. 2019. ISSN 2316-753X. Disponível em: <http://revista.unicuritiba.edu.br/index.php/RevJur/article/view/3404/371371839>. Acesso em: 23 abr. 2020. doi:http://dx.doi.org/10.21902/revistajur.2316-753X.v2i55.3404.

MAGALHÃES. Luiz Felipe Mallmann de. O crime de "Lavagem de Dinheiro". Disponível em < https://www.luizfelipemagalhaes.com.br/artigo/42/crime-de-lavagem-de-dinheiro $>$

MORO, Sergio Fernando. Crime de lavagem de dinheiro. Editora saraiva, 2010. Pena, mariana zopelar almeida de oliveira. Considerações sobre o crime de lavagem de dinheiro e seu bem jurí- dico tutelado. https://www.migalhas.com.br/arquivos/2019/10/art20191015-04.pdf 
RELATÓRIO "The Cash Conection: Organizes Crime, Financial Institutions, and Money Laudering" da President's Comission on Organized Crime de 1985, in: https://www.ncjrs.gov/pdffiles1/Digitization/166517NCJRS.pdf.

SIENA, David Pimentel Barbosa. Crime de "Lavagem de Dinheiro", de acordo com a Lei $\mathbf{n}^{\mathbf{0}}$ 12.683/2012. In: https://jus.com.br/artigos/22899/crime-de-lavagem-de-dinheiro-de-acordocom-a-lei-n-12-683-2012.

http://enccla.camara.leg.br/

https://www.bcb.gov.br/estabilidadefinanceira/lavagemdinheiro

http://agenciabrasil.ebc.com.br/justica/noticia/2019-03/lava-jato-completa-cinco-anos-com155-pessoas-condenadas. 